\title{
The Development of Narrative Reasoning: Student Physical Therapists' Perceptions of Patient Stories
}

\author{
Kathryn C. Nesbit \\ University of the Pacific, cnesbit@pacific.edu \\ Kenneth E. Randall \\ University of Oklahoma Health Sciences Center, Ken-Randall@ouhsc.edu \\ Toby B. Hamilton \\ University of Oklahoma Health Sciences Center, Toby-Hamilton@ouhsc.edu
}

Follow this and additional works at: https://nsuworks.nova.edu/ijahsp

Part of the Education Commons, Physical Therapy Commons, and the Physiotherapy Commons

\section{Recommended Citation}

Nesbit KC, Randall KE, Hamilton TB. The Development of Narrative Reasoning: Student Physical Therapists' Perceptions of Patient Stories. The Internet Journal of Allied Health Sciences and Practice. 2016 Jan 01;14(2), Article 3.

This Manuscript is brought to you for free and open access by the College of Health Care Sciences at NSUWorks. It has been accepted for inclusion in Internet Journal of Allied Health Sciences and Practice by an authorized editor of NSUWorks. For more information, please contact nsuworks@nova.edu. 


\title{
The Development of Narrative Reasoning: Student Physical Therapists' Perceptions of Patient Stories
}

\begin{abstract}
Narrative reasoning is an inductive cognitive strategy used to understand patients' experiences with illness within the biosocial context of their lives. The purpose of this study is to examine the meaning of the patient's illness experience to physical therapist students and propose a theory of narrative reasoning development in these novice clinicians. The data collected from twenty-one first year physical therapy students consisted of narratives written during their clinical internships describing a patient's experience with illness and post-internship interviews telling the patient's story. Data were analyzed in a process of constant comparison, evolving codes, and researcher memoing using both grounded theory and narrative analyses. Themes that emerged in open coding and core categories were validated in selective coding. In the final stage of theoretical coding, relationships between the saturated core categories and relevance to current theory were established. The final result was a model of the development of narrative reasoning, illustrating contributions to current theory. The main themes that emerged from the data related to the novice therapist's development of narrative reasoning were in four areas: perspective, clinical narrative focus, reflective skills, and therapeutic alliance. The theoretical model advanced by this study is a recursive, spiraling developmental process of narrative reasoning through phases that are influenced by drivers and/or barriers. The process includes co-construction of narrative reasoning through encounters with patients, families, clinical instructors and other team members. Establishing a therapeutic alliance is a pivotal point in the development of narrative reasoning and is based on an empathic perspective and strengthened through a reflective approach. In conclusion, this study contributes to the understanding of the development of narrative reasoning. This model of narrative reasoning in student physical therapists has implications for educational interventions aimed at providing learning experiences that parallel the development of narrative reasoning.
\end{abstract}

\section{Author Bio(s) \\ Note to Author}

Need Author Bios as per the example below.

Example: Guy M. Nehrenz, EdD, MA, RRT, is an Executive Associate Dean and Professor of Health Sciences in the College of Health Care Sciences at Nova Southeastern University in Ft. Lauderdale, FL. He is also a licensed respiratory care practitioner in the state of Florida. 


\title{
iJAHSP" \\ Dedicated to allied health professional practice and education
}

The Internet Joưnal of Allied Health Sciences and Practice

Vol. 14 No. 2 ISSN 1540-580X

\section{The Development of Narrative Reasoning: Student Physical Therapists' Perceptions of Patient Stories}

\author{
Kathryn C. Nesbit, PT, DPT, DSc 1 \\ Kenneth E. Randall, PT, PhD, MHR² \\ Toby B. Hamilton, PhD, MPH, OTR/L, FAOTA ${ }^{3}$
}

1. University of Pacific

2. University of Oklahoma

3. University of Oklahoma

United States

\begin{abstract}
Narrative reasoning is an inductive cognitive strategy used to understand patients' experiences with illness within the biosocial context of their lives. The purpose of this study is to examine the meaning of the patient's illness experience to physical therapist students and propose a theory of narrative reasoning development in these novice clinicians. The data collected from twenty-one first year physical therapy students consisted of narratives written after their clinical internships describing a patient's experience with illness and post-internship interviews telling the patient's story. Data were analyzed in a process of constant comparison, evolving codes, and researcher memoing using both grounded theory and narrative analyses. Themes that emerged in open coding and core categories were validated in selective coding. In the final stage of theoretical coding, relationships between the saturated core categories and relevance to current theory were established. The final result was a model of the development of narrative reasoning, illustrating contributions to current theory. The main themes that emerged from the data related to the novice therapist's development of narrative reasoning were in four areas: perspective, clinical narrative focus, reflective skills, and therapeutic alliance. The theoretical model advanced by this study is a recursive, spiraling developmental process of narrative reasoning through phases that are influenced by drivers and/or barriers. The process includes co-construction of narrative reasoning through encounters with patients, families, clinical instructors and other team members. Establishing a therapeutic alliance is a pivotal point in the development of narrative reasoning and is based on an empathic perspective and strengthened through a reflective approach. In conclusion, this study contributes to the understanding of the development of narrative reasoning. This model of narrative reasoning in student physical therapists has implications for educational interventions aimed at providing learning experiences that parallel the development of narrative reasoning.
\end{abstract}

\section{INTRODUCTION}

Narrative reasoning is an inductive cognitive strategy of telling and interpreting stories to inform patient-centered clinical practice. It is the process of understanding patients' experiences with illness within the biosocial context of their lives including beliefs, values, and culture. ${ }^{1}$ The stories that patients tell of their illness experiences include descriptions of their conditions, daily experiences, perspectives on treatment, and perspectives on recovery. ${ }^{2-5}$ These stories engage both the patient and the clinician and are a conduit for the narrative reasoning process. As noted by Coles,

"If our job [is] to help our patients understand what they had experienced by getting them to tell their stories, our job [is] also to realize that as active listeners, we give shape to what we hear, make over their stories into something of our own."6

Narrative reasoning is gaining attention in all healthcare professions, yet the development of narrative reasoning is poorly understood. 3,7 Interview and observational studies of occupational therapists revealed their implicit and explicit use of patient stories as a "central mode of clinical reasoning."8 Narrative reasoning allows practitioners to form collaborative patient-centered plans of care.8,9 The ability to reason using narrative information is a characteristic of expert practice.1,10,11 Experts distinguish themselves 
from novices by their use of narrative reasoning to form a multidimensional knowledge base, link assessments to function, demonstrate a caring attitude, and consider patients as individuals with unique life experiences. ${ }^{12-15}$

Both expert and novice therapists tell stories about patient encounters to make sense of and use the patient's circumstances in developing a patient-centered plan of care. Retelling a patient encounter reveals the novice-narrator's reasoning process by including inherent interpretations of the patients' intentions, goals, and motives. Humans are neurologically hard-wired to use storytelling to make sense of experiences, interpret contexts, and understand needs, intentions, strategies, and motives, both our own and that of others. ${ }^{9}$ Because therapists use stories as a way of making sense of the world, systematic examination of novice's narratives gives insight into their reasoning. ${ }^{8,9} \mathrm{As}$ health care professionals learn to use the reasoning methods articulated by their professions, educators can assess and track the development of that reasoning by having them tell stories about patient encounters. Moreover, a better-informed understanding of narrative reasoning can lead to educational strategies to foster its development.

This study proposes a theory of the development of narrative reasoning in novice student physical therapists. It looks at the way student physical therapists tell the story of their patients' illness experience. In this study, the telling of the patient's story becomes the vehicle for understanding the characteristics of the student physical therapists' narrative reasoning, the factors that contribute to developing narrative reasoning, and the educational interventions that can foster narrative reasoning.

\section{METHODS \\ Study Design}

Two qualitative research designs were used: Constructivist grounded theory and narrative analysis. Grounded theory and narrative analysis are ideal methods for studying the complex phenomenon of the development of reasoning of novices in health care professions. Constructivist grounded theory is a qualitative inductive theory-discovery design using rigorous systematic analysis grounded in robust descriptions that emerge from the data through the interaction between the participant and the researcher. ${ }^{16,17}$ Substantive theory was based on thickly detailed descriptions collected through written narratives, and interviews. The outcome was an articulation of a theory detailing the relationships of the variables that emerge from the data. ${ }^{11,18,19}$ Narrative analysis was used to examine the content and form of the novice's telling of a patient's story. Narratives are interpretive constructions because they involve personal interpretations of the actual experience. As such, student narratives inherently revealed the teller's constructions of experiences that included their version of the patients' needs, intentions, motivations, and strategies. Student physical therapists implicitly used reasoning strategies to interpret what patients told them. The narrative process is illuminated through analysis of what the patient story is about (content) and how the student tells the story (style or form).

\section{Data Collection and Preparation}

The novice clinicians in this study were 21 first year physical therapist students enrolled in the Doctor of Physical Therapy program at the University of the Pacific (volunteers from a class of 34). These students are considered novice clinicians because they were participating in their first full time experience in the clinic setting. The student physical therapists had a background in taking a patient history; however, they had no practice reflecting on the patients' experience with their illness, nor structure for interpreting patient stories or mentorship for co-construction of the patient story with others. They had received no prior coursework in the area of narrative reasoning. Data were collected from written narratives and interviews with the students. The narratives consisted of student physical therapists' written descriptions of an encounter with a patient of the student's choice that took place during their first full-time clinical experience (Appendix 1).

The first author (KN) prepared a semi-structured interview guide shown in Appendix 2. She read the student worksheets and narratives about the encounter before the 20 to 30 minute individual interviews. She audiotaped, transcribed, checked de-identified interview transcripts for accuracy, and stored the texts with students' written narratives on secure servers and password-protected computers. Each student physical therapist comprised a unit of analysis. The University of the Pacific's Institutional Review Board approved this study. Student physical therapists signed an approved informed consent form to participate in the study.

\section{Data Analysis}

All three analysts coded the first two interviews using a 5-cell framework and then discussed them. Figure 1 depicts the 5-cell analysis used for the preliminary coding of the texts. It includes a sample of excerpts from one student physical therapist's data (Student 13). ${ }^{11,20}$

Figure 1. Example (excerpts) of 5-Cell analysis using grounded theory and narrative analysis qualitative design with the one student as the unit of analysis. The 5-cell analysis was adopted from Lieblich, Tuval-Maschiach, \& Zilber (1998).

(c) The Internet Journal of Allied Health Sciences and Practice, 2016 


\begin{tabular}{|c|c|c|c|}
\hline $\begin{array}{l}\text { Data } \\
\text { Student } 13\end{array}$ & $\begin{array}{l}\text { Narrative Content: } \\
\text { Plot or what happens } \\
\text { in the illness narrative, medical } \\
\text { diagnosis, patient prior level of function, } \\
\text { patient beliefs }\end{array}$ & $\begin{array}{l}\text { Grounded Theory Content: } \\
\text { Novice narrative reasoning, } \\
\text { awareness of patient's } \\
\text { perspective }\end{array}$ & $\begin{array}{l}\text { Narrative Form: } \\
\text { How the student tells the } \\
\text { narrative, how the student } \\
\text { describes the patient }\end{array}$ \\
\hline $\begin{array}{l}\text { Categorical } \\
\text { Subsets of } \\
\text { data: } \\
\mathrm{N} \text { (written } \\
\text { narrative) } \\
\text { I (Interview) }\end{array}$ & $\begin{array}{l}\text { an individual who was involved in an } \\
\text { accident on a mountain while snowboarding. } \\
\mathrm{N} 1-2 \\
\text { had a torn meniscus and would need to } \\
\text { undergo surgery N 6-7 } \\
\text { not too long after being home the patient } \\
\text { begin feeling very sick and faint and } \\
\text { returned to the hospital. After a full workup } \\
\text { the doctors notified the patient that when the } \\
\text { person ran into them they jarred loose and } \\
\text { abscess that was located on the patients } \\
\text { spleen and now needed to be removed. } \mathrm{N} 8 \\
-12 \\
\text { he was working for the uh ski mountain but } \\
\text { then, now since it was becoming summer - } \\
\text { they were transferring him to do other stuff. I } \\
84-85 \\
\text { He was going to get back to the way he was } \\
\text { going to be. I } 66\end{array}$ & $\begin{array}{l}\text { Being hospitalized and loosing } \\
\text { thirty pounds really quickly and } \\
\text { being atrophied they just uh and } \\
\text { they were also planning for } \\
\text { weddings and stuff like that so at } \\
\text { this point it was kind of a big deal } \\
\text { um. I 13-15 } \\
\text { Yeah did everything that we told } \\
\text { him even though he sometimes he } \\
\text { said it was just too easy. But we } \\
\text { had to limit his activity because of } \\
\text { the surgeries that he had. I } 44-45\end{array}$ & $\begin{array}{l}\text { he was an easy, straight going } \\
\text { guy. I } 153 \\
\text { It seemed whenever he first } \\
\text { came it he was pretty } \\
\text { discouraged just because it was } \\
\text { more the weight that he had lost } \\
\text { the physical fitness ability he felt } \\
\text { weak um but he was like "I'm } \\
\text { eating as much food as I } \\
\text { possibly can to regain the } \\
\text { weight" and "I want to come here } \\
\text { every time and do what I gotta } \\
\text { do to get back to where I was". I } \\
58-62\end{array}$ \\
\hline $\begin{array}{l}\text { Holistic } \\
\text { (Entire } \\
\text { data) }\end{array}$ & \multicolumn{2}{|c|}{$\begin{array}{l}\text { I guess it was just kind of a good coincidence that they had the accident and so it } \\
\text { was brought to their attention I } 24-25 \\
\text { that's what was important for him to see from us like at the end of the day after we } \\
\text { were done with his exercise routine l'd just kind of show him look we've gone up } \\
\text { this much weight - you've came many calf inch, you've gained this back so } \\
\text { whenever he saw that it just carried over into the next time. I 107-110 }\end{array}$} & $\begin{array}{l}\text { Student kept referring to the } \\
\text { patient as an 'athlete' and } \\
\text { attributed certain characteristics } \\
\text { to that term... such as even } \\
\text { tempered, not frustrated, } \\
\text { resilient. }\end{array}$ \\
\hline Memo & \multicolumn{3}{|c|}{$\begin{array}{l}\text { Very positive patient experience; this patient stood out to the student in a positive way; as the student said, "We kind of } \\
\text { clicked. We got along fairly well." }\end{array}$} \\
\hline
\end{tabular}

Two analysts (KN and KR) coded the texts of the 21 student narratives and interview and wrote a summary for each student. After completing this process, all three analysts examined texts across students until the researchers reached data saturation by finding no new information. Applying the grounded theory approach, the researchers read each interview and written narrative line-by-line looking for patterns in open coding, reviewed, labeled (coded), constantly compared data for fit and relevance, and wrote successive memos to capture thoughts and abstractions. The researchers worked independently before comparing results at weekly teleconferences and reconciled differences by referring to the data until they reached consensus about initial codes. They combined related codes (for example, hammer, nail, wrench) into superordinate categories (tools). Through theoretical sampling, they constantly compared and memoed from selective text to validate or disconfirm relationships between concepts and noted variations. The researchers diagrammed concrete relationships of categories to develop constructive theories grounded in how novice therapists constructed the meaning of patients' stories. For example, they determined that a key factor in developing narrative reasoning is the ability to acknowledge the existence of perspectives other than one's own. After accounting for all data, the researchers constructed and refined their explanatory model. They then compared it to other explanatory theories and asked participants for feedback on the model. The outcome is a model of the development of narrative reasoning, illustrating its contributions to current theory. Figure 2 is a flow chart of the data analysis. ${ }^{16,18}$

Figure 2. Data collection and analysis 
$\downarrow \quad$ Written narratives of a patients' story

20-30 minute interviews

5-Cell Analysis

$\downarrow \quad$ Individual cases

Open Coding using constant comparison and memoing

$\downarrow$ Coding of individual cases $\rightarrow$ constant comparison across cases

Emergence of core categories (themes)

Selective Coding using constant comparison and memoing

$\downarrow$ Core categories are saturated

Most relevant categories emerge

Direction of research is focused

Relationships between categories emerge from constant comparison

Construction and refinement of explanatory models

\section{Theoretical Coding}

$\downarrow$ Comparison to existing theory/literature

Development of a Theoretical Model contributing to existing theory

Member checking

\section{Study Rigor}

Throughout this process, the researchers were confident that the findings were credible (internally valid and grounded in the data), dependable (found in the data or reliable), and confirmable (objective). Qualitative findings are particular to the participants and not transferable without adaptation to novel circumstances (externally valid). The researchers achieved rigor using established methods of thick descriptions, audit trails, and peer review. 11,21,22 They used triangulation of sources (student physical therapists' written notes and interview transcripts) and methods (grounded theory and narrative analysis), and included member checking in their grounded theory process.

\section{RESULTS}

\section{Main themes}

The main themes that emerged from the data related to the student physical therapist's development of narrative reasoning in four areas: perspective, clinical narrative focus, reflective skills, and establishment of a therapeutic alliance. These themes led to our model depicting the development of narrative reasoning as a co-constructed process by the student, the patient, and others. Both drivers and barriers influenced the development of narrative reasoning.

\section{Development of the novice therapist's perspective: Pre-student to clinician}

Many of the students' stories about their patients mentioned their pre-student experiences. One student's sports background led to identification with the patient as an athlete (Student 3). Another recognized that the patient "reminded me of my mom" (Student 5). Some reported an awareness of a shift in their perceptive as students, to their role as novice clinicians in the patient's recovery: "I couldn't imagine having to go through something so difficult...There was nothing I could do to solve this man's current living situation." (Student 14)

\section{Development of the clinical narrative focus: From uncertainty to patient-centered}

The student's stories suggest a developmental continuum of the focus of the clinical narrative from uncertainty about the medical condition, to applying only biomedical information, to including the patient's psychosocial aspects, to appreciating patient-centered goals, to recognizing of the influence of the patient's personal factors on these goals, and finally, to understanding the meaning of the goal in a real-life context. Following are examples of these developmental benchmarks.

Some students were uncertain of the medical condition but with guiding questions by the interviewer $(\mathrm{KN})$ were able to articulate the patient's perspective on functional problems:

$\mathrm{KN}$ : What words did he use did he use to describe [his condition]?

Student 4: So, I don't know if he actually knew the exact term of his condition. Um, he just knew that there was something wrong with him.

$\mathrm{KN}$ : What do you think he thought his problem was? 
Student 4: He knew for sure he had a walking problem.

Other narratives, however, focused on the biomedical status of the patient: "He could feel himself getting stronger and stronger and you could see it too because we had obviously taken measurements and stuff like that and he could see each week how he was getting it back" (Student 3). Many student stories focused on psychosocial factors that contributed to their patients' illness experience: "In the beginning, I dismissed her lack of understanding of her mental illness as an altered mental status that came with aging, but in the end, I realized it was most likely due to her lack of hope" (Student 9). A student described how recovery was influenced by the patient's fear of falling: "Since he didn't have the proper gait, he was afraid that if he didn't catch himself, he could damage something else in his body" (Student 4).

In some stories, students were able to describe patient-centered functional goals: "He performs a lot of lifting for his two jobs....[He is] looking to get back to the level that he was" (Student 17). Many narratives included information about the physical and social contexts of the patient's illness. The descriptions focused on functional loss in the areas of social participation, mobility, work productivity and activities of daily living: "So with his job, he was required to pick up basically those big Rubbermaid@ trashcans.... Work's important to him because he's the sole breadwinner for his household. And his wife also had some medical complications" (Student 17).

\section{Development of the reflective skills: Gathering multiple perspectives}

Several stories lacked contemplative elements indicating underdeveloped reflective skills, whereas in others, the students' reflections on their patient's illness experience showed an appreciation for the family's perspective, their personal biases, the challenging aspects of providing therapy, and insight into their professional roles. Following are examples from our data, beginning with a reflection on the patient's family:

I felt a connection with this patient and often became sad for how this [the patient's condition] affected her family life... I don't know if "sad" is the right word, but if made me like just feel for her situation and her family's because her husband seems to be very like heavy because of the whole situation... he just said, "This is hard." (Student 20)

Other students reflected on their personal biases: "Everybody has their differences...her definition of nice was definitely not my definition of nice" (Student 12). Students also commented on their reaction to therapy sessions: "[lt was] a bit of a challenging experience" (Student 12). Other students reflected on ways to motivate patients: "The hardest part was finding something to make him highly motivated. [For this young child with developmental delays] play was a huge motivation and [so was] snack" (Student 3). Reflection on the collaborative role of the therapist emerged in some student stories:

My experience with this patient really opened my eyes to the therapist's role, not only as a means to aid the patient to reach their highest quality of life, but also as a means to identify when a patient needs to be referred to another area of the medical field to help in recovery. (Student 15)

Development of the therapeutic alliance: Building shared understanding

Empathy was the critical characteristic of the stories that showed the development of a therapeutic relationship. This therapeutic alliance was based on trust and collaboration and built on shared understanding of the patient's perspective. ${ }^{23}$ One student was close to tears telling his story in the interview. He not only noticed the verbal and nonverbal cues expressing the patient's thoughts and feelings, but also was aware of his own empathic response. Note how he formed a shared awareness of the patient's concerns and the effect of the illness on the patient:

Their [patient and husband] relationship I know was threatened by this situation [patient's health condition], so that was a whole other aspect that is, I am sure is difficult for patients. It just tears me up - not only does she have a physical condition.... it threatens their relationship. (Student 1)

In light of the patient's illness experience, he understood that therapy was more than exercises:

And by the end of the, usually by the end of the appointment, she felt good. Like verbalize and being able to talk to somebody. It was almost like therapeutic, being able to talk to me and tell me about her past, and whatever. Just to be able to talk, and show some movement - even though she was shaky she was still able to do the exercises and that made her feel better. (Student 1)

(c) The Internet Journal of Allied Health Sciences and Practice, 2016 
In contrast, stories that lacked empathy were more focused on biomedical aspects with a tendency to be egocentric and judgmental: "[The patient's] physical appearance was off-putting...you walk up to someone like that and your see their leg and it's like - so [should] I put gloves on to touch their leg?" (Student 19).

\section{Model of the Development of Narrative Reasoning}

The theoretical model advanced by this study is a recursive, spiraling developmental process of narrative reasoning that advances through phases that are influenced by various drivers and/or barriers. Figure 3 depicts the model of narrative reasoning development. It depicts stages of pre-student, student, and clinician that led first to the diagnosis-centered and later to the patientcentered narrative.

\section{Figure 3. Model of Narrative Reasoning Development}

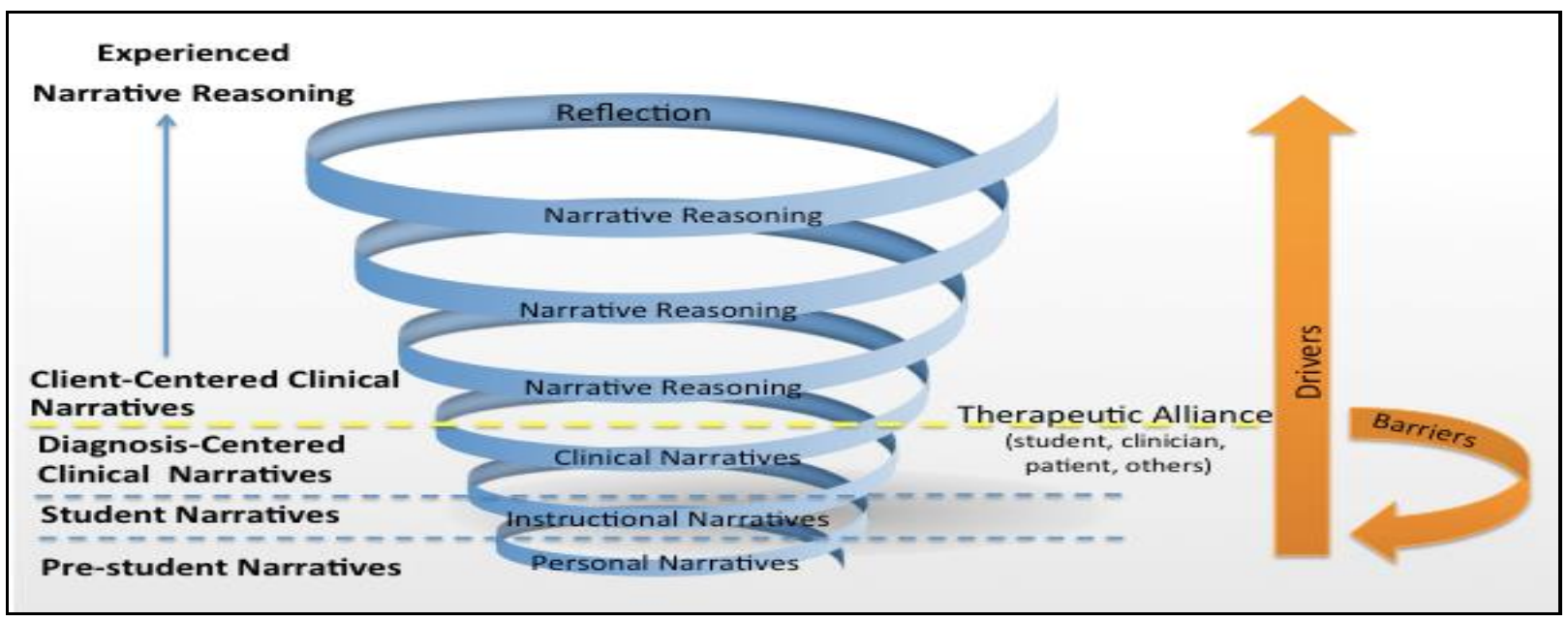

With the formation of the therapeutic alliance and ongoing reflection, the spiral process of narrative reasoning development continues upward. Figure 4 is an expansion of the drivers and barriers that influence narrative reasoning development at the point where the therapeutic alliance is established.

Figure 4. Expansion of the drivers and barriers that influence narrative reasoning development at the point where the therapeutic alliance is established.

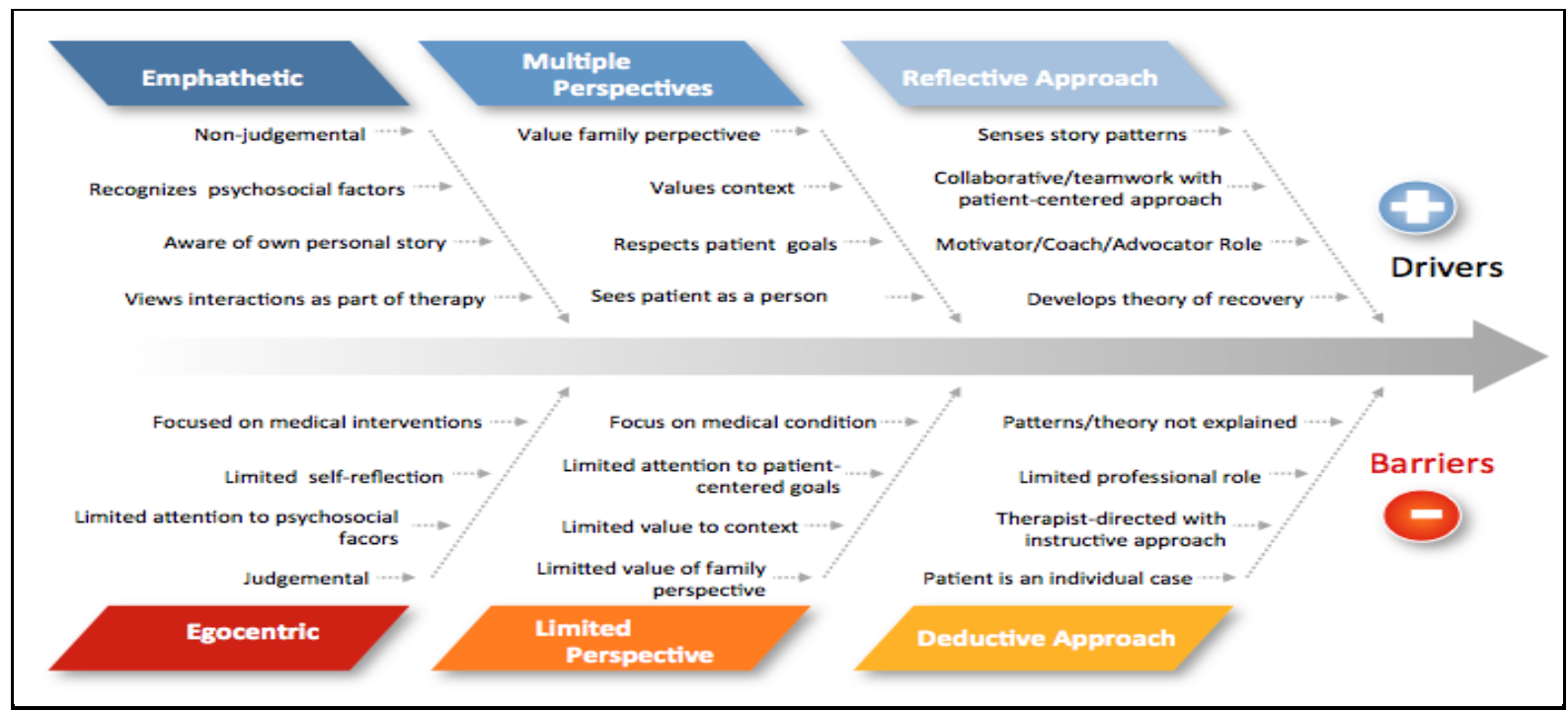

Students construct narratives as developing clinicians from contact with faculty, peers, and academic content as they progress through the curriculum. Reasoning from personal and student narratives allows them to assimilate the academic content. Initial diagnosis-centered clinical narratives develop from early clinical experiences based primarily on academic topics dealing with 
scientific reasoning of learned diagnoses, evaluation, and intervention. At this level, student physical therapists connect impairments with diagnoses, follow protocols for evaluation, and provide intervention on a patient-to-patient basis. Subsequent patient-centered clinical narratives build on diagnosis-centered reasoning and add multiple perspectives (patients, family, contexts) to help the novice clinicians to establish functional goals and personalize interventions in a plan of care.

Narrative reasoning depends on the recurring synthesis of cumulative diagnosis-centered and patient-centered reasoning. Those who achieve empathic patient-centered reasoning reflect and process information from multiple perspectives, such as patients, families, referral and reimbursement sources, peers, and supervisors. Reflection is an important metacognitive skill that fosters development of higher levels of reasoning. ${ }^{24}$ The therapeutic alliance between the novice, the patient, and others occurs at a critical point where drivers lead to further development of narrative reasoning, and barriers lead to a stagnant repetitive cycle.

During the member-checking portion of this qualitative study, students validated the contributions to theory in this model:

I agree that novice therapists have room to grow/evolve through patient connections. It makes complete sense that a therapist with empathy will be more invested. I feel like even a novice therapist who does show empathy can also use hypo-deductive reasoning.

Although most of us have a very analytical mindset during clinicals, I feel that our connections and relationships we build with patients allow us to be empathetic and/or motivating. I feel that we can also tell when our patient needs us to take a more empathetic role of motivating role depending on our patient's emotions.

These new things do seem on target. It might be difficult to teach narrative reasoning to certain novice therapists; examples of how to do that with difficult people would be good. It can be hard to show empathy as a novice therapist because you're so focused on the patient's symptoms.

\section{DISCUSSION}

Narrative reasoning is recognized as an essential part of making patient-centered clinical decisions. However, in the current literature, the novice's perspective of the patient's story has not yet been explored. This study contributes to current theory by describing the iterative process of the development of narrative reasoning in student physical therapists and its potential drivers and barriers. The process includes co-construction of narrative reasoning through encounters with patients, families, clinical instructors, and other team members. Establishing a therapeutic alliance is a pivotal point in the development of narrative reasoning and is based on novices having an empathic perspective that is strengthened through a reflective approach.

According to several studies, expert physical therapists use knowledge from multiple sources and relate findings to function with a patient-centered approach. ${ }^{12,25,26}$ They value the patient's perspective and reflect on the patient's illness experience in a biopsychosocial context.1,14,20,26-29 One student physical therapist in our study illustrated this in her comment, "She [the patient] also wished to gain greater range of motion in her shoulders so she could complete household chores" (Student 16).

Frank ${ }^{4}$ describes patterns in patient stories that tell of restitution of health, chaos of no change or improvement, and quest in which the illness experience is a journey itself. The story context has importance to the connections between the medical condition and its impact on the patient's quality of life .3,12 While Frank's work is related to the medical profession as a whole and not a specific therapy discipline, the student physical therapists' perceptions of their patients' stories showed Frank's patient story patterns of restitution: "He did not want to accept the idea of compensation for his condition and only desired a cure" (Student 2); chaos: "[the patient's says following an unexpected illness] Where do we go? Why me? Why did this happen to me?" (Student 17); and quest: "[patient reflects on his past] You know if someone would have told me at least not to drink so much maybe this wouldn't have happened... just need to get used to it [gait unsteadiness]" (Student 4).

Reflection is an important element of practice as well as a tool for educating novice therapists. ${ }^{30,31}$ Sandars defines reflection as "a metacognitive process that creates greater understanding of self and situations to inform future action." ${ }^{2}$ Wainwright noted that experienced therapists tend to reflect on patient-therapist interactions and on their professional experience more than novice therapists. ${ }^{33}$ Following is an illustration of a student developing reflection:

I think his perception [not wanting to use a brace]...debilitated him. Because it didn't enable him to think about the positive things that he could do with compensation... It was like he was living in the past or living in other people instead of living in the present of what he could do (Student 2).

The analysis of the narratives of novices illuminated key differences in student physical therapists who had a focus on what Mishler termed the patient's lived experience, or "voice of the life world" in contrast to those who had bio-scientific focus on symptoms and

(c) The Internet Journal of Allied Health Sciences and Practice, 2016 
etiology, or the "voice of medicine." ${ }^{34,35}$ The presence or absence of empathy influences the therapeutic alliance that is central to the expert physical and occupational therapists" appreciation for the patient's perspective. ${ }^{15,26,36,37}$ One student physical therapist in our earlier example clearly invoked his innate empathic motivation and empathic communication skills to realize that conversation can be as therapeutic as exercise (Student 1). In contrast, student physical therapists who do not get past the restricted perspective of the patient as a disease or condition were unable to advance in their narrative reasoning ${ }^{38}$ (as illustrated in Student 19).

Student therapists and their patients participate in collaborative "story making" through their clinical interactions. ${ }^{37}$ Cognitive theories based in the work of Piaget and Vygotsky suggest that novice learners co-construct meaningful narratives through exchanges with others and organize experiences through established mental processes. ${ }^{39-44} \mathrm{An}$ example of co-construction is found in Student 3 who gathered information from multiple perspectives - the teacher and her clinical instructor -- in order to see the child's individual attributes and appreciate how they influence therapy: "[He was] very temperamental...overall a friendly little kid.... play was a huge motivation and snack" (Student 3). The student used this information to determine that snack and play were motivators in therapy.

\section{Implications for Health Sciences Education}

This model of narrative reasoning in student physical therapists has implications for educational interventions aimed at providing learning experiences that parallel the development of narrative reasoning. Early course work might consist of an introduction to narrative reasoning in didactic experiences that prepare students for transition to the clinic. Subsequent clinical experiences can involve students using narratives to describe their patients and collaborative experiences with other professionals.

Educators can use scaffolding as a guided discovery approach with an emphasis on active learner participation. For example, guided questions incorporated into a robust narrative presented to students as a paper patient scenario can link multiple perspectives to intervention planning:

From this story, please summarize in your own words the perspective of the family member in this narrative. What value do you place on this information in helping guide your development of a treatment plan for the patient?

Student self-assessments of their narrative reasoning and calibration with their peers can occur during "debriefing" or "processing" activities that begin with individual self-reflection by students and progress to group sessions with classmates. The instructor can provide explicit support in the form of observations, positive feedback, or questions that promote a reflective approach and employ the drivers to development of narrative reasoning. Scaffolding can facilitate development of student reasoning when barriers exist. The following examples of questions may foster student growth in key areas related to narrative reasoning:

How did/would you structure the patient interview to gain information about the patient's everyday life? How would this guide you in care planning and goal setting?

What personal biases did you take into the clinic experience?

How do you understand empathy and how it influences patient care? How would you describe your ability to empathize with your patients?

\section{Limitations and Conclusions}

This study aims to meet high standards of rigor for narrative and grounded theory qualitative analysis. The quality of this study and its outcomes are supported through the thick descriptions, audit trails, peer review, triangulation, and member checking. The researchers have combined qualitative approaches to increase the depth of the analysis by considering both the form and content of the novice therapist's stories of their patient experiences with illness (narrative analysis) and the theory about the development of the novice therapist that is revealed through the construction of stories (grounded theory). The model in this study is neither tested nor based on an analysis of a student physical therapist's development over time. The influence of the student physical therapist's perception of the patient story on their management of the patient was not addressed and is an area for further investigation through a longitudinal study design. The data gathered was limited to the group selected and may not be generalizable to all student physical therapists.

In conclusion, this study contributes to current theory by describing a preliminary model of the iterative process of narrative reasoning development in student physical therapists and the drivers and barriers that may influence it. The process includes coconstruction of narrative reasoning through encounters with patients, families, clinical instructors, and other team members. Establishing a therapeutic alliance is a pivotal point in the development of narrative reasoning and is based on an empathic perspective and strengthened through a reflective approach. The study provides the background for future studies that examine the model, investigate the specific steps in the process of narrative reasoning development, and evaluate the effectiveness of teaching interventions based on the model.

(c) The Internet Journal of Allied Health Sciences and Practice, 2016 


\section{REFERENCES}

1. Edwards I, Jones M, Carr J, Braunack-Mayer A, Jensen GM. Clinical reasoning strategies in physical therapy. Phys Ther. 2004 Apr;84(4):312-30; discussion 331-5. [PMID: 15049726]

2. Bleakley A. Stories as data, data as stories: making sense of narrative inquiry in clinical education. Med Educ. 2005;39(5):534-40. [PMID: 15842721]

3. Charon R. Narrative Medicine: Honoring the Stories of Illness. New York, NY: Oxford University Press; 2006.

4. $\quad$ Frank A. The Wounded Storyteller,2e. Chicago, IL: The University of Chicago Press; 2013.

5. Kleinman A. The Illness Narratives: Suffering, Healing, and the Human Condition. New York, NY: Basic; 1988.

6. $\quad$ Coles R. The Call of Stories. Boston, MA: Houghton Miffin Company; 1989.

7. Charon R. The patient-physician relationship. Narrative medicine: A model for empathy, reflection, profession and trust. JAMA. 2001;286(15):1897-1902. doi:10.1001/jama.286.15.1897. [PMID 11597295]

8. Mattingly C. The narrative nature of clinical reasoning. Am J Occup Ther. 1991;45(11):998-1005. [PMID: 1793123]

9. Hamilton T. Narrative Reasoning. In: Schell B, Schell J, editors. Clinical and Professional Reasoning in Occupational Therapy. Philadephia, PA: Lipincott Willams \& Wilkins; 2008. p. 125-68.

10. Greenfield $\mathrm{BH}$, Jensen $\mathrm{GM}$. Understanding the lived experiences of patients: application of a phenomenological approach to ethics. Phys Ther. 2010;90(8):1185-97. [PMID: 20539020]

11. Patton M. Qualitative Research and Evaluation Methods,3e. Thousand Oaks: Sage Publications; 2002.

12. Jensen GM, Gwyer J, Shepard KF, Hack L. Expert practice in physical therapy. Phys Ther. 2000;80(1):28-43. [PMID: 10623958]

13. Jensen GM, Gwyer J, Hack L, Shepard KF. Expertise in Physical Therapy Practice. St. Louis, MO: Saunders Elsevier; 2007.

14. Atkinson HL, Nixon-Cave K. A tool for clinical reasoning and reflection using the International Classification of Functioning, Disability and Health (ICF) framework and patient management model. Phys Ther. 2011;91(3):416-30. [PMID: 21273627]

15. Greenfield BH, Anderson A, Cox B, Tanner MC. Meaning of caring to 7 novice physical therapists during their first year of clinical practice. Phys Ther. 2008;88(10):1154-66. [PMID: 18719004]

16. Charmaz K. Constructing Grounded Theory,2e. Thousand Oaks, CA: Sage Publications; 2014.

17. Breckenridge J, Jones D, Elliott I, Nicol M. Choosing a methodological path: reflections on the constructivist turn. Grounded Theory Review. 2012;11(1):e1-8.

18. Jones M, Alony I. Guiding use of grounded theory in doctoral studies - an example from the Australian film industry. International Journal of Doctoral Studies. 2011;6:95-113.

19. Sbaraini A, Carter SM, Evans RW, Blinkhorn A. How to do a grounded theory study: a worked example of a study of dental practices. BMC Med Res Methodol. 2011;11:128. [PMID: 21902844]

20. Lieblich A, Tuval-Maschiach R, Zilber T. Narrative Research: Reading, Analysis and Interpretation. Thousand Oaks CA: Sage Publications; 1998.

21. Lincoln Y, Guba E. Naturalistic Inquiry. Beverly Hills, CA: Sage Publications; 1985.

22. Guba E. Criteria for assessing the trustworthiness of naturalistic inquires. ERIC Annual Review. 1981;29:75- 91.

23. Norfolk T, Birdi K, Walsh D. The role of empathy in establishing rapport in the consultation: a new model. Med Educ. 2007;41:690-7. [PMID: 17614890]

24. Schell B, Shell J. Clinical and Professional Reasoning in Occupational Therapy. Philadephia, PA: Lippincott Williams \& Wilkins; 2008.

25. Edwards I, Jones M. Clinical reasoning and expert practice. In: Jensen G, Gwyer J, Hack L, Shepart K, editors. Expertise in Physical Therapy Practice,2e. St. Louis, MO: Saunders Elsevier; 2007. p. 192-213.

26. Jensen G, Resnik L, Haddad A. Expertise and clinical reasoning. In: Higgs J, Jones M, Loftus A, Christensen N, editors. Clinical Reasoning in the Health Professions,3e. Philadelphia PA: Butterworth-Heinemann; 2008. p. 123-35.

27. World Health Organization. International Classification of Functioning, Disability and Health: ICF. Geneva Switzerland: World Health Organization; 2001.

28. Wainwright SF, Shepard KF, Harman LB, Stephens J. Factors that influence the clinical decision making of novice and experienced physical therapists. Phys Ther. 2011;91(1):87-101. [PMID: 21127167]

29. Jette AM. Toward a common language for function, disability, and health. Phys Ther. 2006;86(5):726-34. [PMID: 16649895]

30. Mann K, Gordon J, MacLeod A. Reflection and reflective practice in health professions education: a systematic review. Adv Health Sci Educ Theory Pract. 2009;14(4):595-621. [PMID: 180343364] 
31. Schon D. Educating the Reflective Practitioner: Toward a New Design for Teaching and Learning in the Professions. San Francisco, CA: Jossey-Bass; 1987.

32. Sandars J. The use of reflection in medical education. AMEE Guide No. 44. Med Teach. 2009;31(8):685-95. [PMID: 19811204]

33. Wainwright SF, Shepard KF, Harman LB, Stephens J. Novice and experienced physical therapist clinicians: a comparison of how reflection is used to inform the clinical decision-making process. Phys Ther. 2010;90(1):75-88. [PMID: 19926680]

34. Mishler E, Clark J, Ingelfinger J, Simon M. The language of attentive patient care. J Gen Intern Med. 1989;4(4):325-35. [PMID: 2668459]

35. Mishler E. The Discourse of Medicine: Dialectics of Medical Interviews. Santa Barbara, CA: Greenwood Publishing Group; 1984.

36. Jensen GM, Paschal KA. Habits of mind: student transition toward virtuous practice. J Phys Ther Ed. 2000;14(3):42-7.

37. Mattingly C, Fleming M. Clinical Reasoning. Philadelphia, PA: FA Davis Company; 1994.

38. Taylor R. The Intentional Relationship: Occupational Therapy and the Use of Self. Philadelphia, PA: F. A. Davis Company; 2008.

39. Bodner G. Constructivism: A theory of knowledge. J Chem Educ. 1986;63:873-8.

40. Liu CH, Matthews R. Vygotsky's philosophy: Constructivism and its criticisms examined. Int Ed J. 2005;6(3):386-99.

41. Piaget J. The Development of Thought: Equilibrium of Cognitive Structures. New York, NY: Viking; 1977.

42. Jacoby S, Ochs E. Co-construction: An introduction. Research on Language \& Social Interaction. 1995;28(3):171.

43. Popkewitz D. Dewey, Vygotsky, and the social administration of the individual: Constructivist pedogogy as systems of ideas and historical spaces. Am Educ Res J. 1998;35(4):535-70.

44. Vygotsky L. Thought and Language: MIT Press; 1962. 


\section{APPENDIX 1}

Written Narrative Prompt

Choose a patient you provided physical therapy for in your first two-week clinical experience. In about 250-300 words (one page double spaced), describe the patient's experience with his or her illness. Do not include the patient's name/age/address or other identifying information about their physical appearance, name of the facility, or any medical information from the patient's written chart. You will not be graded on this narrative response. 


\section{Interview Guide}

\section{APPENDIX 2}

Thank you for agreeing to participate in this interview. This interview is part of a study we are doing on the meaning of patient illness experiences to physical therapist students. I am interested in learning about what physical therapy students understand about the patient's experience with their illness. The interview should take about 20 minutes. I would like to audiotape this interview so that I can transcribe it later and analyze it for my study. This interview will be confidential. I not be using any names of people or places in my study, and the information from the study will be published in a peer-reviewed journal. I will also review my findings with you. You will not be graded on this interview. As we go through the interview feel free to ask my any questions about why I am asking you something. If there is anything you don't want to answer, just say so - you don't have to talk about anything you don't want to. You can stop the interview at any time. Do you have any questions? Are you willing to participate in this interview? Do not include the patient's name/age/address or other identifying information about their physical appearance, name of the facility, any medical information from the patient's written chart.

Question 1: Tell me about the patient you wrote about in your narrative.

Probes: Talk more about that

I'd like to hear more about that

Clarifying: It is correct that you ...(my summary of the description)?

Question 2: Tell me what your patient thought was the problem, why he had a problem, or what he thought caused the problem.

Probes: Tell me using the patient's words

Tell me more about his description of his condition

Tell me about how the patient said he got information about his condition

Clarifying: Is it correct your patient thought his condition was caused by... (my summary of the student's description).

Question 3: Describe your patient's daily experience with his condition?

Probe: What did your patient tell you about how his illness impacted his daily life?

Describe your patient's day, or part of his day, as the patient described his experience.

Would you give me an example of how the patient's condition impacted his day?

Would you elaborate on that?

Talk more about that

l'd like to hear more about that

I am not sure I understand what you mean by "...."

Tell me again

Clarifying: Is it correct that your patient's daily experience his condition disability...(my summary of the experiences with disability).

Question 4: What did your patient expect from physical therapy treatment?

Probe: Would you give me an example?

Would you elaborate on that?

Talk more about that

l'd like to hear more about that

I am not sure I understand what you mean by "..."

Tell me again

Clarifying: Have I understood correctly that... (my summary of the patient expectations)?

Question 5: Describe your patient's hopes for recovery, his feelings about getting better.

Probe: Would you give me an example?

Would you elaborate on that?

Talk more about that

l'd like to hear more about that

I am not sure I understand what you mean by "..."

Tell me again

Clarifying: You have told me that your patient had these views on his recovery...(my summary).

Question 6: Describe how what you learned about the patient's perspective on his illness influenced the physical therapy treatment, goals, and recovery process.

Probe: How did you know that you understood the patient's experience?

(c) The Internet Journal of Allied Health Sciences and Practice, 2016 
What adjustment did you make in your treatment that was a result of your understanding of the patient's experience with his condition?

What goals did you formulate that were a result of your under understanding of the patient's experience with his condition?

How do you feel the patient's experience influenced his recovery process?

Tell me more about this.

Could you give me an example?

Please elaborate on that

Clarifying: You have told me that your understanding of your patient's experience with his illness influenced your....(my summary).

Closing: You have been very helpful. What other thoughts or feelings would you like to share with me to help me understand your patient's experience with his illness? What would you like to add? 